\title{
Transport properties of Si based nanocrystalline films investigated by c-AFM
}

\author{
Maria Antonietta Fazio a, Martina Perani ${ }^{a}$, Nils Brinkmann ${ }^{\text {b, }}{ }^{\text {, }}$, Barbara Terheiden ${ }^{\mathrm{b}}$, \\ Daniela Cavalcoli ${ }^{\text {a, * }}$ \\ a Department of Physics and Astronomy, University of Bologna, Italy \\ ${ }^{\mathrm{b}}$ Department of Physics, University of Konstanz, Germany
}

Keywords:

Silicon thin film

Conductive AFM

Photovoltaics

PECVD

\begin{abstract}
A B S T R A C T
$\mathrm{SiO}_{\mathrm{x}} \mathrm{N}_{\mathrm{y}}$ is an innovative material that has recently attracted a lot of attention in different and new applications, ranging from photovoltaics, conductive oxide, carbon capture; nevertheless, due to its complex and multiphase nature, the understanding of its electrical properties is still ongoing. In this framework, the present manuscript presents the investigation of electrical transport properties of nanocrystalline (nc-) $\mathrm{SiO}_{\mathrm{x}} \mathrm{N}_{\mathrm{y}}$. In fact, non-stoichiometric $\mathrm{nc}_{-} \mathrm{SiO}_{\mathrm{x}} \mathrm{N}_{\mathrm{y}}$ films deposited by Plasma Enhanced Chemical Vapor Deposition have been studied by conductive Atomic Force Microscopy (AFM). The analyses of samples subjected to different thermal treatments conditions and the comparison with nc-Si:H films have allowed us to clarify the role of crystallization and $\mathrm{O}$ content on the local conductivity of the layers. We show that the annealing treatment promotes an enhancement of conductance, a redistribution of the conductive grains in the layers and the activation of B doping. Current-voltage characteristics locally performed using the conductive AFM-tip as a nanoprobe have been modelled with thermionic emission transport mechanism.
\end{abstract}

\section{Introduction}

Silicon oxy-nitride $\left(\mathrm{SiO}_{\mathrm{x}} \mathrm{N}_{\mathrm{y}}\right)$ is an innovative material for different applications. For example, $\mathrm{SiO}_{\mathrm{x}} \mathrm{N}_{\mathrm{y}}$ layers are employed as dielectric in metal-insulator-metal capacitors [1], as core layer in integrated optics devices [2,3] as well as in the photovoltaic field, as rear passivation layer in monocrystalline silicon solar cells [4].

In the last field, $\mathrm{SiO}_{\mathrm{x}} \mathrm{N}_{\mathrm{y}}$ thin films can be used in Si-based heterojunction solar cells as the heteroemitter stack layers. In fact, these layers can substitute the hydrogenated amorphous silicon (a$\mathrm{Si}: \mathrm{H}$ ) thin films, since high parasitic light absorption is reduced by the introduction of $\mathrm{O}$ and $\mathrm{N}$ atoms, resulting in a larger band gap and high conductivity [5]. $\mathrm{SiO}_{\mathrm{x}} \mathrm{N}_{\mathrm{y}}$ doped layers are able to reach an energy gap of $2.5 \mathrm{eV}$ and electrical conductivity of $44 \mathrm{~S} / \mathrm{cm}$ [6]. Our

\footnotetext{
* Corresponding author. Physics and Astronomy Dept, University of Bologna, viale C Berti Pichat 6/II, 40127 Bologna, Italy.

E-mail addresses: maria.fazio2@unibo.it (M.A. Fazio), martina.perani2@unibo.it (M. Perani), nils.h.brinkmann@gmail.com (N. Brinkmann), Barbara.Terheiden@ uni-konstanz.de (B. Terheiden), daniela.cavalcoli@unibo.it, cavalcoli@bo.infn.it (D. Cavalcoli).

1 Present address: Beamreach Solar, 1530 McCarthy Blvd, CA-95035, USA.
}

recent studies have reported on the variation of nanoscale morphology and structural and compositional characteristics of these layers with different deposition conditions [6,7], showing annealing-induced phase separation, with a formation of Si-rich and O-rich areas due to oxygen relocation within the layers [6]. This separation, together with the increase of crystalline fraction upon annealing, has been related to the increase of the macroscopic conductivity [6]. Although these results have brought new interesting information on $\mathrm{SiO}_{\mathrm{x}} \mathrm{N}_{\mathrm{y}}$ thin layers, an investigation on how the deposition parameters can affect the electrical properties at the nanoscale has not been achieved yet. Intriguing properties have been only recently observed; as an example, new studies have shown that realistic device voltages can create some major nanoscale structural and chemical changes in metastable amorphous silicon-rich silicon oxides, due to migration of oxygen ions [8].

Conductive Atomic Force Microscopy (c-AFM) is an excellent non-destructive technique to investigate electrical properties of different materials at the nanoscale, even in ambient conditions. In fact, it has been used to analyse resistive switching behaviour of systems for memory applications [9-11], variations in the electrical properties at different deposition parameters [12,13], and local electrical properties or degradation sites in different layers and 
how they are correlated to the device performance [14,15].

C-AFM is very useful to study the electrical properties also of individual nanostructures, due to the presence of the tip working as a metalized probe, which has the function of an electrical contact $[16,17]$. The tips allow for the extraction of local current-voltage characteristics that can be useful to investigate the transport model of the electrical conduction at the nanoscale $[18,19]$.

C-AFM can also be used for more exotic and newer purposes, for example, for growing single gold filaments at the tip apex and for switching the local phase at nanometric scale of phase-change materials for nano-display application, by applying a voltage bias between the tip and the sample in peculiar ambient conditions $[20,21]$.

In this work, c-AFM technique has been used to study the nanometric transport electrical properties of B doped silicon oxynitride deposited with different parameters and to extract a model of electrical conduction in these materials. C-AFM has been applied also to hydrogenated nanocrystalline silicon films in order to clarify the role of $\mathrm{O}$ and $\mathrm{N}$ on the conductivity.

Several studies, both theoretical [22,23] and experimental $[24,25]$, have been made on the correlation between the dimensions of Si nanocrystals, the impurity solubility and the dopant efficiency. However, the role of dopant in more complex and multiphase materials, such as $\mathrm{SiO}_{\mathrm{x}} \mathrm{N}_{\mathrm{y}}$ thin films, is still unclear.

Within this framework, this work provides a thorough investigation of $\mathrm{SiO}_{\mathrm{x}} \mathrm{N}_{\mathrm{y}}$ thin films electrical properties at the nanoscale, in samples with various oxygen content and crystalline fraction. The research aims to collect a precise information on the role of oxygen and nitrogen and of the B activation in the electrical conductivity of the samples. As a comparison, hydrogenated nanocrystalline silicon samples are also investigated.

Moreover, it has been possible, through the extraction of current-voltage characteristics, to evaluate a consistent transport model for the high conductive areas of the samples.

\section{Experimental methods}

P-type $\mathrm{SiO}_{\mathrm{x}} \mathrm{N}_{\mathrm{y}}$ layers are deposited by Plasma Enhanced Chemical Vapor Deposition (PECVD) on FZ-Si substrate with a commercial system (PlasmaLab 100 from Oxford Instrument) in a parallel plate configuration. The deposition temperature is $300{ }^{\circ} \mathrm{C}$ and the radio frequency (RF) is set at $13.56 \mathrm{MHz}$. Silane $\mathrm{SiH}_{4}$, hydrogen $\mathrm{H}_{2}$ and nitrous oxide $\mathrm{N}_{2} \mathrm{O}$ are used as precursor gases. To achieve ptype doping, diborane $\left(\mathrm{B}_{2} \mathrm{H}_{6}\right)$ diluted in hydrogen $(0.5 \%)$ was used. The flow of $\mathrm{N}_{2} \mathrm{O}$ and the ratio of $\mathrm{B}_{2} \mathrm{H}_{6}$ are both referred to their dilution in silane. Then, their ratios can be defined, respectively, as:

$R_{\mathrm{N}_{2} \mathrm{O}}=\frac{\left[\mathrm{N}_{2} \mathrm{O}\right]}{\left[\mathrm{N}_{2} \mathrm{O}\right]+\left[\mathrm{SiH}_{4}\right]}$

$R_{B_{2} H_{6}}=\frac{\left[B_{2} H_{6}\right]}{\left[B_{2} H_{6}\right]+\left[\mathrm{SiH}_{4}\right]}$

where the square brackets represent the gas concentrations. $\mathrm{SiO}_{\mathrm{x}} \mathrm{N}_{\mathrm{y}}$ doped layers are deposited with $\mathrm{R}_{\mathrm{B} 2 \mathrm{H} 6}=2.34 \%$ and then annealed at $800{ }^{\circ} \mathrm{C}$ in a nitrogen atmosphere to promote nanocrystals formation. $\mathrm{SiO}_{\mathrm{x}} \mathrm{N}_{\mathrm{y}}$ doped samples revealed the presence of Si crystallized fraction [6,7]. We will call them $n c-\mathrm{SiO}_{\mathrm{x}} \mathrm{N}_{\mathrm{y}}$ for sake of clarity.

Nitrous oxide and diborane dilutions, annealing time, thickness and crystalline fraction of the samples are reported in Table 1 . The thickness is calculated by ellipsometry measurements, while the $\mathrm{Si}$ crystallized fraction is extracted by Raman spectroscopy [6]. The samples are labelled according to their annealing time, the as- deposited samples are referred as $0 \mathrm{~h}$ annealed samples.

Our previous studies have shown that both nitrous oxide dilution and thermal treatment cause variations in the properties of the samples. An increase of the $\mathrm{N}_{2} \mathrm{O}$ dilution corresponds to an increment of the $\mathrm{O}$ content within the layers, while the $\mathrm{N}$ remains almost the same [26]. Moreover, the two parameters $\left(\mathrm{N}_{2} \mathrm{O}\right.$ dilution and annealing) affect the crystallinity fraction within the layers. This property is strictly linked to the macroscopic electrical properties of the samples, that is, the conduction enhances in samples with higher crystalline fraction [6]. Samples with higher oxygen content show worse electrical properties, while the annealing process promotes electrical conduction [6]. The last enhancement is probably correlated to oxygen relocation due to the thermal treatment and formation of O- and Si- rich areas within the samples [6]. Moreover, annealing affects the surface morphological properties of the samples as well, that is, the surface roughness and the structures dimensions on the surface increase in the annealed samples [7].

In addition to $\mathrm{SiO}_{\mathrm{x}} \mathrm{N}_{\mathrm{y}}$ samples, hydrogenated nanocrystalline silicon (nc-Si:H) thin layers have been grown by PECVD on FZ-Si at $225{ }^{\circ} \mathrm{C}$, with $\mathrm{SiH}_{4}, \mathrm{H}_{2}$ and $\mathrm{B}_{2} \mathrm{H}_{6}$ as precursor gases. $\mathrm{H}_{2}$ dilution is referred to silane too, defined as:

$R_{\mathrm{H}_{2}}=\frac{\left[\mathrm{H}_{2}\right]}{\left[\mathrm{H}_{2}\right]+\left[\mathrm{SiH}_{4}\right]}$

The hydrogen dilution of the nc-Si:H samples is $R_{H 2}=91 \%$.

Conductive-AFM (c-AFM) measurements allow for the investigation of local differences in the conductivity at the nanoscale $[27,28]$. The acquisitions were performed using a Park NX10 system in contact mode with Pt probe (RMN 25Pt300B), with tip radius smaller than $20 \mathrm{~nm}$. A fixed bias is applied to the sample through the ohmic contact made with conductive silver paste on the top side of the sample. In order to avoid the well-known problem of the wearing of the tip [25], fresh tips were always used. Several maps on the same sample were acquired, in order to check their reproducibility. In each sample small interaction forces, ranging from 600 to $650 \mathrm{nN}$, have been used to avoid artefacts and the damaging of the tips. We investigated always fresh areas of the samples, preventing a local oxidation effect; this approach is also useful to avoid hysteresis effects in the current-voltage characteristics. The effect of the tip - contact distance on the current values was checked and always similar and reproducible c-AFM maps were obtained. The current that flows between the tip and the sample is extracted from the tip and then amplified and recorded in each point of the map. In the present arrangement, holes and electrons currents are measured for positive and negative bias applied to the sample, respectively.

With c-AFM, current-voltage (I-V) characteristics have been obtained in different selected highly conductive points of the sample by continuous and linear variation of the bias applied to the sample.

\section{Results}

Conductive properties at the nanoscale of the thin layers have been measured by c-AFM technique. $1 \times 1 \mu \mathrm{m}^{2}$ maps of $512 \times 512$ px have been acquired at constant bias applied to the sample, both negative and positive, and I-V characteristics have been extracted in highly conductive points of the samples.

Among several nc-SiO ${ }_{\mathrm{x}} \mathrm{N}_{\mathrm{y}}$ samples grown with different deposition conditions, the samples reported in Table 1 have been selected in order to analyse the effects of crystalline fraction and $\mathrm{N}_{2} \mathrm{O}$ content on the nanoscale electrical properties. In more detail, as shown in Table 1, the samples COh and C3h have been grown 
Table 1

Deposition parameters and characteristics of the investigated samples.

\begin{tabular}{|c|c|c|c|c|c|}
\hline Sample (label) & $\mathrm{R}_{\mathrm{N} 2 \mathrm{O}}(\%)$ & Annealing $(\mathrm{h})$ & $\mathrm{R}_{\mathrm{B} 2 \mathrm{H} 6}(\%)$ & Thickness (nm) & Crystalline fraction (\%) \\
\hline nc-SiO $\mathrm{N}_{\mathrm{y}}(\mathrm{C} 3 \mathrm{~h})$ & 9.09 & 3 & 2.34 & 209 & 88 \\
\hline $\mathrm{nc}-\mathrm{SiO}_{\mathrm{x}} \mathrm{N}_{\mathrm{y}}(\mathrm{COh})$ & 9.09 & 0 & 2.34 & 209 & 67 \\
\hline $\mathrm{nc}-\mathrm{SiO}_{\mathrm{x}} \mathrm{N}_{\mathrm{y}}(\mathrm{E} 3 \mathrm{~h})$ & 47.4 & 3 & 2.34 & 283 & 70 \\
\hline nc-Si:H (SiA) & 0 & 0 & 2 & 18 & $<5$ \\
\hline nc-Si:H (SiB) & 0 & 0 & 2 & 55 & 60 \\
\hline
\end{tabular}

with the same $\mathrm{N}_{2} \mathrm{O}$ content, but they have a different annealing time resulting in different crystallinity. The sample E3h has the same annealing time of $\mathrm{C} 3 \mathrm{~h}$, but it has been grown with higher $\mathrm{N}_{2} \mathrm{O}$ content which results in lower crystallinity with respect to C3h [6].

It has already been shown from SIMS measurements that, with increasing $\mathrm{R}_{\mathrm{N} 2 \mathrm{O}}$, the oxygen content rises, while nitrogen concentration remains almost unchanged [26]. As O within the layers increases, both crystallinity fraction and electrical conductivity decrease [6]. After the deposition, the annealing process promotes recrystallization of the $\mathrm{nc}-\mathrm{SiO}_{\mathrm{x}} \mathrm{N}_{\mathrm{y}}$ samples, demonstrated through an increase of the crystalline fraction [6]. In addition, thermal process induces clustering of grain-like structures on the sample surface and boosts the optical bandgap up to $2.5 \mathrm{eV}$ [7].

Regarding the nc-Si:H samples, a very abrupt transition from the amorphous to the nanocrystalline phase occurs as the $\mathrm{R}_{\mathrm{H} 2}$ dilution increases; this transition is accompanied by a large variation in the dark conductivity of the samples $[29,30]$. Due to the island-like growth of the crystallites, both crystallinity and macroscopic conductivity increase with the layer thickness $[30,31]$. In the present work two samples of nc-Si:H have been investigated with different thicknesses, but same deposition conditions; it is to be noted that the different thicknesses result in a different crystal fraction (Table 1).

Fig. 1(a), (c) and (e) report AFM topography maps of the nc$\mathrm{SiO}_{\mathrm{x}} \mathrm{N}_{\mathrm{y}}$ samples $\mathrm{C} 3 \mathrm{~h}, \mathrm{COh}$ and E3h (Table 1 ), respectively, whereas, Fig. 1(b), (d) and (f) show the corresponding current maps. The lowest values of applied bias capable to give measurable signals have been used, in order to reduce tip induced damage and possible artefacts in the maps [32]. The maps here reported are typical examples; for each sample, several maps of different sizes have been obtained. As the substrate of these samples has a higher electrical resistance with respect to the one of the layer, we can assume that the c-AFM maps reflect the transport properties of the nc-SiO $\mathrm{N}_{\mathrm{y}}$ layers. Both topography and current maps show the presence of grain-like structures on the surface, probably formed by nanocrystals clustering [6]. The grains correspond to the highest conductive areas (the lighter ones in the current maps at positive bias) and they are embedded into an amorphous and less conductive matrix. The grain conductivity is affected by annealing time and/or oxygen content. In order to achieve quantitative information on this effect, the comparison between the conductance distributions of the as-deposited sample ( $\mathrm{COh})$ with the annealed ones ( $\mathrm{C} 3 \mathrm{~h}$ and $\mathrm{E} 3 \mathrm{~h}$ ) over a reduced conductivity range [0-100 pS] is reported in Fig. 1(g) both for negative and positive bias.

COh and E3h show a high number of counts at negative bias, while $\mathrm{C} 3 \mathrm{~h}$ at positive bias. This means that before annealing ( $\mathrm{COh})$ and after annealing but for high $\mathrm{O}$ content (E3h), the main contribution to the electrical current comes from the electrons, while after annealing and for low $\mathrm{O}$ content $(\mathrm{C} 3 \mathrm{~h})$, the holes contribution to the current prevails.

Different distribution shapes can also be observed, as well as a different distribution of the conductive grains over the maps. In order to quantitatively evaluate this difference, the approach showed in Fig. 2 was used.
The distributions of conductance obtained at negative applied bias are reported in their entire range in Fig. 2(a)-(c). It can be noted that the conductance range spreads over four orders of magnitude (from 0.04 to $100 \mathrm{nS}$ for negative bias), while the conductance value corresponding to the highest probability shifts from 2 to $16 \mathrm{pS}$ from the less to the most conductive samples. To better observe the differences in the distribution of the high conductive grains over the maps, an arbitrary threshold is fixed at $20 \%$ of all the counts, separating the high conductive tail (red bins) from the low conductive peak (grey bins). This threshold is then reported in the current maps (the insets of Fig. 2(a)-(c)). As the pictures show, in the most conductive layer ( $\mathrm{C} 3 \mathrm{~h}$ ) the high conductive grains agglomerate forming clusters, while in the less conductive samples the high conductive points are more homogeneously distributed within the map. It must be reminded here that the layer $\mathrm{C} 3 \mathrm{~h}$ has evidenced coalescence and clustering of nanocrystals and $O$ relocation [6].

Fig. 3 reports the morphological ((a)-(c)) and current ((b)-(d)) maps for two nc-Si:H samples with different thicknesses obtained with a negative applied bias. The grains represent the highest conductive areas in the maps (the darker ones) and their dimensions increase and number decreases with the sample thickness. This change is probably due to the clustering of the island-like crystalline structures as the deposition time increases. The crystallites show different conductivities, whose range is affected also by the sample thickness (shown in Fig. 3). Macroscopically, we expected that the thicker sample ( $\mathrm{SiB})$, which shows also the highest crystallinity [29], would be more conductive than the thinner one (SiA). However, in the present microscopic maps the reverse occurs. The microscopic transport is affected by the fact that in sample SiB the current must pass through a large amorphous non-conductive area (Fig. 3(d)), which is wider with respect than the equivalent area in sample SiA (Fig. 3(b)). Moreover, larger grain boundaries are present, due to the crystallites clustering, which add a further resistance in the current path. The distribution of conductivity values for negative and positive applied bias is reported in Fig. 3(e). It must be noted here that the main contribution to the current for both the samples comes from hole flow.

Local I-V characteristics have been measured at different high conductive points of the $\mathrm{nc}-\mathrm{SiO}_{\mathrm{x}} \mathrm{N}_{\mathrm{y}}$ samples. An example is shown in Fig. 4(a) for E3h sample, and the experimental setup is sketched in the inset. I-V curves on the amorphous non-conductive regions are not reported as they show almost null current in this bias range.

Stable and reproducible I-V curves have been always obtained; the different I-V curves in Fig. 4(a) are a consequence of the difference in the electrical conductivity of the grains, probably due to their dimensions and dopant inclusion.

These I-V characteristics are usually modelled as back-to-back Schottky contacts [33]. The tip-sample contact is considered as a Schottky contact and the electronic conduction can be modelled through thermionic-emission mechanism [34]. In this mechanism, the emission of free carriers through the interface between the metal and the semiconductor of the Schottky barrier is taken into account as the fundamental limiting factor in the electrical 

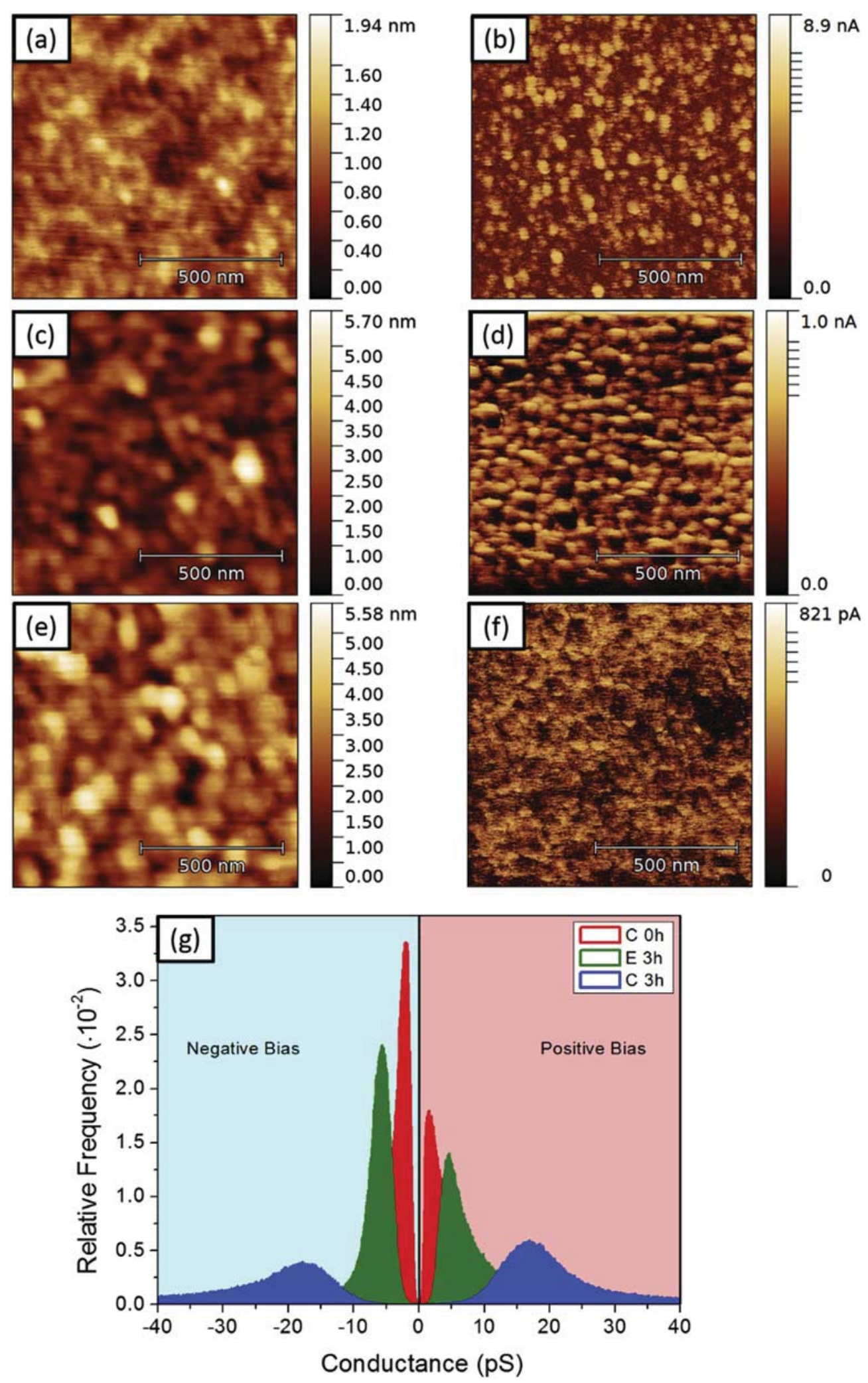

Fig. 1. Morphological and current maps, respectively, of (a)-(b) nc-SiO $\mathrm{N}_{\mathrm{y}}$ samples $\mathrm{C} 3 \mathrm{~h}$ at $0.1 \mathrm{~V}$, (c)-(d) COh at $1.5 \mathrm{~V}$ and (e)-(f) E3h at $0.4 \mathrm{~V}$. All the morphological maps are reported in linear scale, while current maps are in non-linear scale. (g) Conductance distributions for $\mathrm{COh}$ (red), $\mathrm{E} \mathrm{h}$ (green) and $\mathrm{C} 3 \mathrm{~h}$ (blue) nc-SiO $\mathrm{N}_{\mathrm{y}}$ samples for negative (light blue) and positive (light red) applied biases. Negative conductance values refer to negative applied values. (For interpretation of the references to colour in this figure legend, the reader is referred to the web version of this article.) 

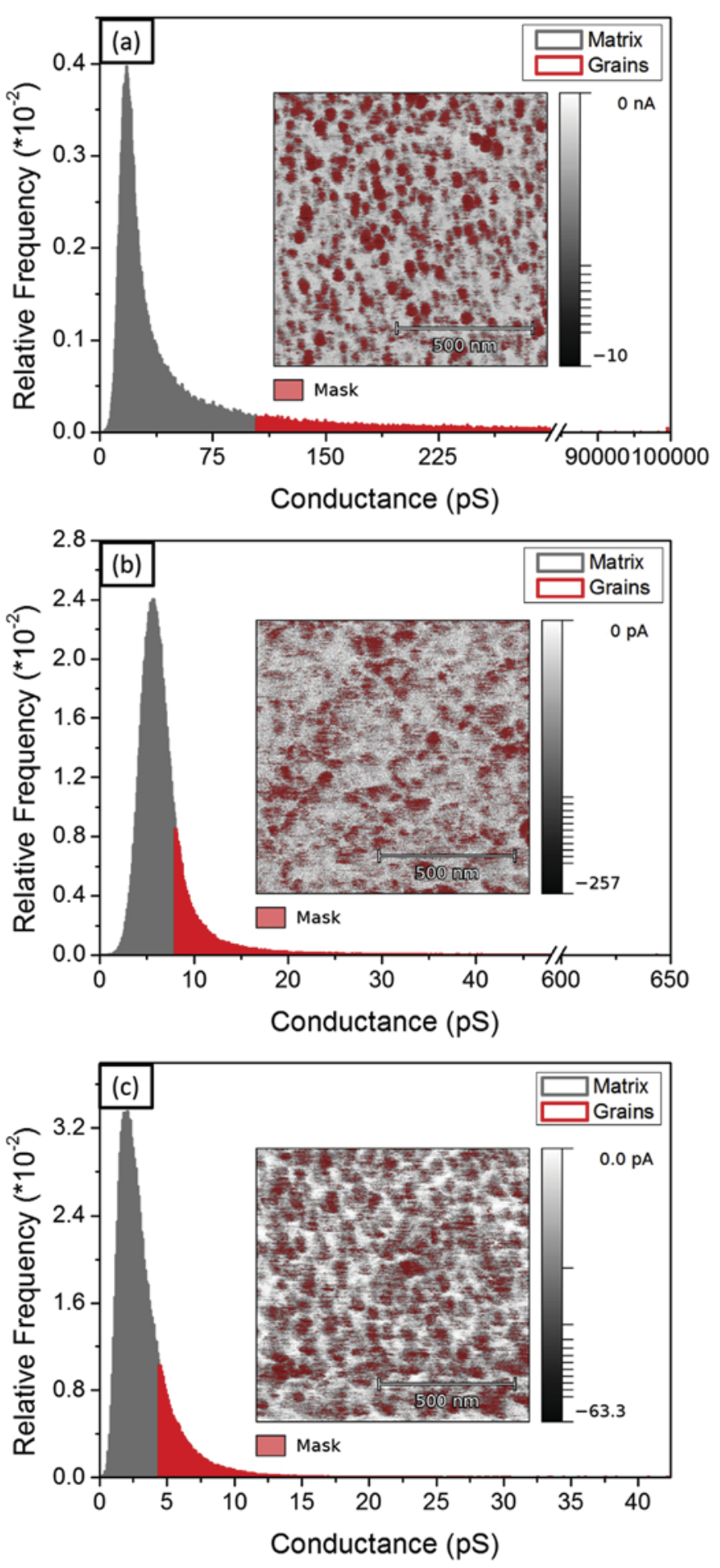

Fig. 2. Conductance distributions for negative biases of (a) C3h $(-0.1 \mathrm{~V})$, (b) E3h

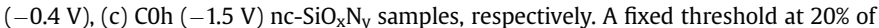
all counts separates the high conductive contribution (red tail) from the low conductive one (grey peak). Corresponding current maps are reported in the respective insets, in non-linear scale. (For interpretation of the references to colour in this figure legend, the reader is referred to the web version of this article.)

conduction [35]. In this case, the Schottky barrier is formed between the metallic tip and the semiconductor high conductive areas of the $\mathrm{SiO}_{\mathrm{x}} \mathrm{N}_{\mathrm{y}}$ and $\mathrm{nc}-\mathrm{Si}: \mathrm{H}$ samples. According to the thermionic-emission theory, the current-voltage characteristics at low applied voltages $\left(\mathrm{V}<3 \mathrm{k}_{\mathrm{B}} \mathrm{T} / \mathrm{q}\right)$ and reversed applied voltages are described by the following non-ideal equation:

$J=J_{0} e^{q V / n k_{B} T}\left[1-e^{-q V / k_{B} T}\right]$

where $J_{0}=A^{* *} e^{-q \varphi_{B} / k_{B} T}$ is the inverse saturation density current, $q$ is the elementary electrical charge, $n$ the ideality factor, $V$ the applied bias to the junction, $k_{B}$ the Boltzmann constant, $A^{* *}$ the Richardson's constant and $\varphi_{B}$ the barrier height of the junction [35]. By means of equation (4), parameters such as the ideality factor $n$ and the barrier height $\varphi_{B}$ can be extracted [35]. This method is also effective to analyse back-to-back real ohmic contacts, in order to extract their junction parameters [36].

In Fig. 4(b) a selection of the experimental data of the E3h sample of $\ln \left(\mathrm{I} /\left(1-\exp \left(-\mathrm{qV} / \mathrm{k}_{\mathrm{B}} \mathrm{T}\right)\right)\right)$ for negative biases and the corresponding fit are shown as black squares and red line, respectively. $\mathrm{Nc}^{-} \mathrm{SiO}_{\mathrm{x}} \mathrm{N}_{\mathrm{y}}$ E3h sample I-V characteristic is fitted according to equation (4). Similar analyses have been carried out for all the samples listed in Table 1, and a very good agreement between the experimental and calculated I-V curves has been always obtained. Table 2 lists the fitting parameters: the ideality factor $n$ and the height of the Schottky barrier $\varphi_{B}$ between the metallic tip and the high conductive areas of the samples. The values here reported show that the thermionic-emission model is consistent, since the values of ideality factor $n$ are around 1 and $\varphi_{B}$ is of the same order of magnitude of the value relevant to $\mathrm{Pt} / \mathrm{Si}$ junction $(0.5 \mathrm{eV})[35,37]$. The errors on $\varphi_{B}$ are overestimated, to take into account the large uncertainties of quantities estimated from literature data (such as Richardson constant, temperature at the junction, and tip-sample contact area). It must be noted that some differences among the samples are present: the more conductive samples show a lower $\varphi_{B}$ in the high conductive areas. In fact, the most conductive sample C3h (both macroscopically [6] and at the nanoscale) shows the lowest barrier to the conduction from the conductive grains to the tip.

\section{Discussion}

Conductive-AFM studies have allowed us to obtain an in-depth characterization of the microscopic electrical properties of nc$\mathrm{SiO}_{\mathrm{x}} \mathrm{N}_{\mathrm{y}}$, through the analysis of samples deposited with different $\mathrm{O}$ content and annealing treatment. A comparison with nc-Si:H has allowed us to clarify the role of $\mathrm{O}$ and $\mathrm{N}$ content and annealing treatment on the microscopic electrical properties.

We can summarize the results obtained as follows.

In all the samples investigated, the c-AFM maps show conductive grains embedded in a less conductive (likely amorphous) matrix, similarly to previous results obtained on nc-Si $[25,26]$. In this respect, $\mathrm{nc}-\mathrm{SiO}_{\mathrm{x}} \mathrm{N}_{\mathrm{y}}$ shows transport properties similar to the ones of nc-Si:H; however, marked differences in the conductivity values and grain distribution arise when the different deposition conditions are considered. It should be reminded that all these samples are B doped.

The comparison between $\mathrm{SiO}_{\mathrm{x}} \mathrm{N}_{\mathrm{y}}$ samples with the same $\mathrm{O}$ content, but different annealing time ( $\mathrm{COh}$ and $\mathrm{C} 3 \mathrm{~h}$ ) shows that:

i) The annealing treatment enhances the Si crystallized fraction which, in turns, enhances conductivity in agreement with macroscopic measurements reported elsewhere [6].

ii) The annealing promotes a redistribution of the conductive grains, which coalesce after $3 \mathrm{~h}$ of annealing. This redistribution is probably related to the annealing induced oxygen relocation, which can cause the marked separation between 

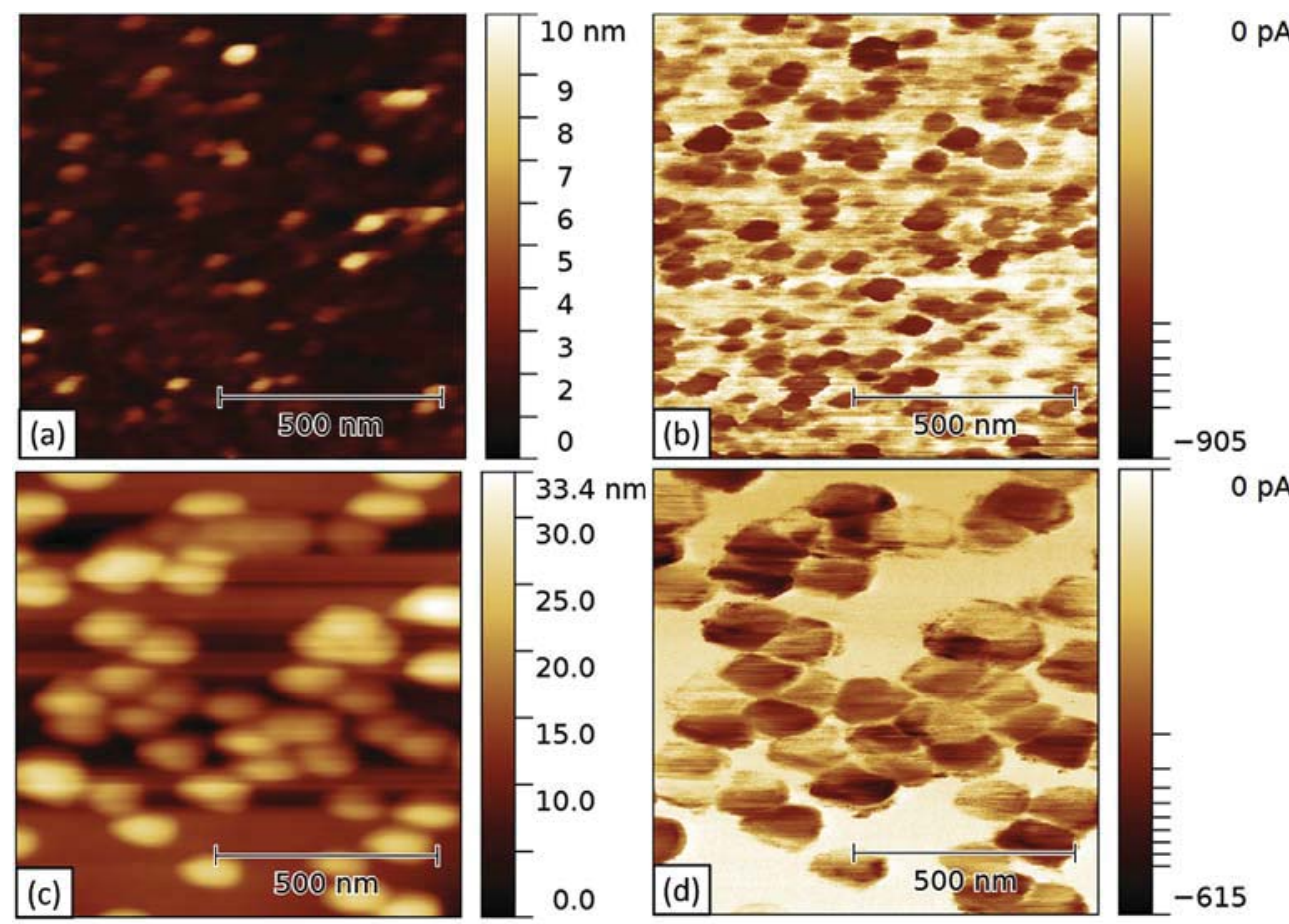

$0 \mathrm{pA}$

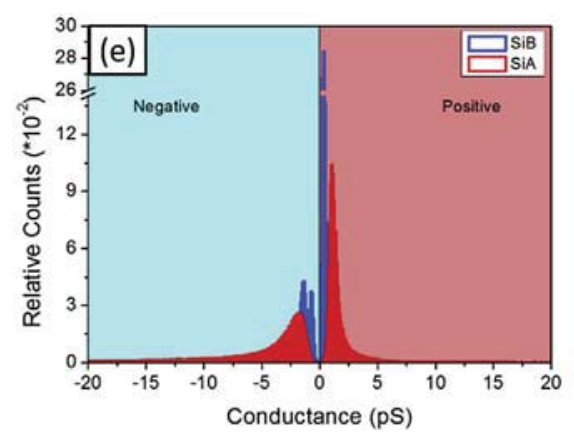

Fig. 3. Morphological and current maps, respectively, of (a)-(b) SiA and (c)-(d) SiB nc-Si:H samples with $-1.5 \mathrm{~V}$ and $-2.5 \mathrm{~V}$ negative applied biases. (e) Conductance distributions for $\mathrm{SiB}$ (blue) and SiA (red) nc-Si:H samples for negative (light blue) and positive (light red) applied biases. Negative conductance values refer to negative applied values. All morphological maps are reported in linear scale, while current maps are in non-linear scale. (For interpretation of the references to colour in this figure legend, the reader is referred to the web version of this article.)

well-shaped high conductive grains and the likelyamorphous matrix [6].

iii) The annealing affects the transport properties of the layers: COh shows a higher contribution of electrons, while C3h of holes on the overall current flow. This means that, for samples with low $\mathrm{O}$ content, the holes contribution to the current prevails over the electrons contribution after annealing.

The comparison between samples with the same annealing conditions, but different $\mathrm{O}$ content (C3h, low $\mathrm{N}_{2} \mathrm{O}$ dilution, E3h, high $\mathrm{N}_{2} \mathrm{O}$ dilution), shows that:

i) High O content prevents the achievement of high Si crystallized fraction, and, thus, high conductivity.

ii) High $\mathrm{O}$ content prevents the enhancement of holes flow as E3h sample shows enhanced electrons flow.

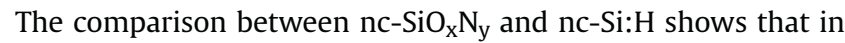
the latter hole transport prevails; however, nc-Si:H has a lower conductivity with respect to $\mathrm{nc}-\mathrm{SiO}_{\mathrm{x}} \mathrm{N}_{\mathrm{y}}$.

\section{Conclusions}

Therefore, we can conclude that the presence of $\mathrm{O}$ and $\mathrm{N}$ in the matrix enhances the overall conductivity of the thin films, but they contrast the dopant ( $\mathrm{B}$ in the present case) activation. From the conductance analysis, we can observe that $\mathrm{B}$ is active as a dopant in nc-Si:H, but in order to achieve its activation in $\mathrm{SiO}_{\mathrm{x}} \mathrm{N}_{\mathrm{y}}$ films, low $\mathrm{O}$ content and a $3 \mathrm{~h}$ long annealing treatment are required. The incorporation of nitrogen and oxygen induces an increase of disorder [6,28] and B atoms in these samples mostly passivate disorder-induced defects and n-type conduction prevails. Upon annealing, crystal disorder decreases and grain clustering occurs, resulting in $\mathrm{B}$ activation, as a transition from defect passivation to free carrier generation occurs. A similar effect has been observed for P doped Si nanocrystals (NCs) [38]. B does not activate in high O content $\mathrm{SiO}_{\mathrm{x}} \mathrm{N}_{\mathrm{y}}$ layers due to high disorder and $\mathrm{O}$ induced n-type conductivity.

Similar conclusions on the B role have been reached by theoretical studies that predicted that large Si NCs can easily sustain doping. Moreover, group III impurities introduce acceptor levels in the gap of the Si NCs that become shallower as the size of the Si NCs 

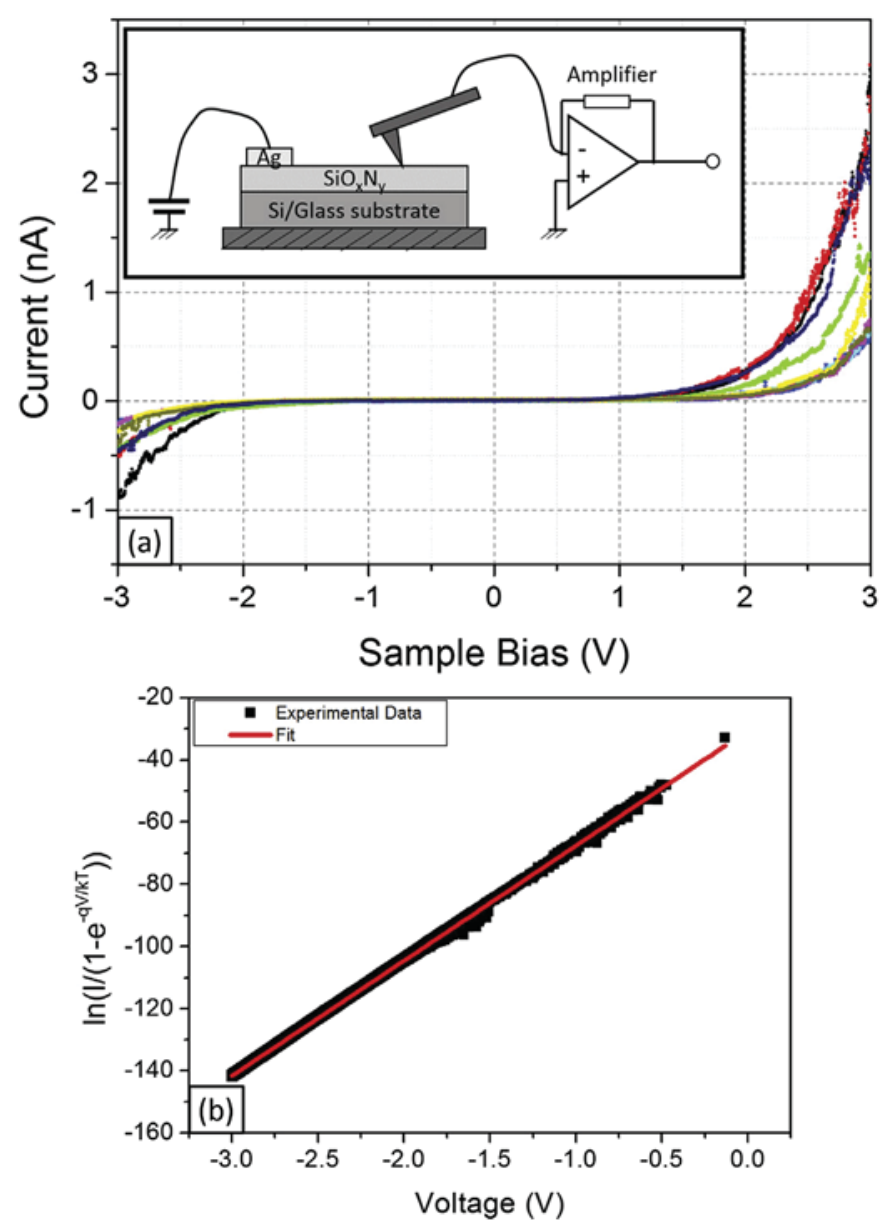

Fig. 4. (a) Example of several I-V characteristics for E3h nc-SiO $\mathrm{N}_{\mathrm{y}}$ sample with a varying bias from $-3 \mathrm{~V}$ to $3 \mathrm{~V}$ measured on the conductive regions. I-V curves on the amorphous non-conductive regions are not reported as they show null current in this bias range. The inset shows a scheme of the experimental setup. (b) Selection of $\ln (\mathrm{I} /$ $\left(1-\exp \left(-\mathrm{qV} / \mathrm{k}_{\mathrm{B}} \mathrm{T}\right)\right)$ ) experimental data for $\mathrm{E} 3 \mathrm{~h} \mathrm{nc}-\mathrm{SiO}_{\mathrm{x}} \mathrm{N}_{\mathrm{y}}$ sample (black squares) and the corresponding fit (red line). (For interpretation of the references to colour in this figure legend, the reader is referred to the web version of this article.)

Table 2

Extracted parameters of the investigated samples from equation (4).

\begin{tabular}{lll}
\hline Sample (label) & $n$ & $\varphi_{B}(\mathrm{~V})$ \\
\hline $\mathrm{nc}-\mathrm{SiO}_{\mathrm{x}} \mathrm{N}_{\mathrm{y}}(\mathrm{C} 3 \mathrm{~h})$ & $0.9924 \pm 0.0008$ & $0.42 \pm 0.04$ \\
$\mathrm{nc}-\mathrm{SiO}_{\mathrm{x}} \mathrm{N}_{\mathrm{y}}(\mathrm{COh})$ & $1.0422 \pm 0.0008$ & $0.61 \pm 0.07$ \\
$\mathrm{nc}-\mathrm{SiO}_{\mathrm{x}} \mathrm{N}_{\mathrm{y}}(\mathrm{E} 3 \mathrm{~h})$ & $1.0445 \pm 0.0006$ & $0.60 \pm 0.07$ \\
$\mathrm{nc}-\mathrm{Si}: \mathrm{H}(\mathrm{SiA})$ & $1.088 \pm 0.001$ & $0.7 \pm 0.1$ \\
$\mathrm{nc}-\mathrm{Si}: \mathrm{H}(\mathrm{SiB})$ & $1.0032 \pm 0.0005$ & $0.44 \pm 0.04$ \\
\hline
\end{tabular}

increases [22,23]. Experimental studies on nc-Si:H [24,25] also confirmed this effect.

The fit of I-V characteristics reported in Fig. 4 shows a very nice agreement between experimental data and the proposed model, demonstrating that the current flow from the tip to the conductive grains is controlled by a thermionic-emission process. Free carriers are emitted over the tip/sample barrier. The obtained barrier height values scale with the different conductivities of the films, indicating that local I-V can successfully probe the transport properties quantitatively and at the nanoscale.

The present study has allowed us to clarify the role of $\mathrm{O}, \mathrm{N}, \mathrm{B}$ content and annealing treatment on the microscopic transport properties of Si based thin films for photovoltaic applications.

\section{References}

[1] C.H. Ng, K.W. Chew, S.F. Chu, Characterization and comparison of PECVD silicon nitride and silicon oxynitride dielectric for MIM capacitors, IEEE Electron Device Lett. 24 (8) (2003) 506-508.

[2] K. Wörhoff, A. Driessen, P.V. Lambeck, L.T.H. Hilderink, P.W.C. Linders, Th.J.A. Popma, Plasma enhanced chemical vapor deposition silicon oxynitride optimized for application in integrated optics, Sens. Actuators A- Phys. 74 (1) (1999) 9-12.

[3] J. Schmitz, B. Rangarajan, A.Y. Kovalgin, Fabrication and properties of GeSi and SiON layers for above-IC integrated optics, Solid-State Electron. 108 (2015) $8-12$.

[4] H. Yang, E. Wang, H. Wang, W. Guo, Industrial technology of passivated emitter and rear cells with silicon oxynitride and silicon nitride as rear passivation for high efficiency BIPV modules, Energy Proced. 88 (2016) 389-393.

[5] Z.C. Holman, A. Descoeudres, L. Barraud, F.Z. Fernandez, J.P. Seif, S. De Wolf, C. Ballif, Current losses at the front of silicon heterojunction solar cells, IEEE J. Photovolt. 2 (1) (2012) 7-15.

[6] M. Perani, N. Brinkmann, A. Hammud, D. Cavalcoli, B. Terheiden, Nanocrystal formation in silicon oxy-nitride films for photovoltaic applications: optical and electrical properties, J. Phys. Chem. C 119 (24) (2015) 13907-13914.

[7] M. Perani, N. Brinkmann, M.A. Fazio, A. Hammud, B. Terheiden, D. Cavalcoli, Annealing effects on $\mathrm{SiO}_{\mathrm{x}} \mathrm{N}_{\mathrm{y}}$ thin films: optical and morphological properties, Thin Solid Films 617 (2016) 133-137.

[8] A. Mehonic, M. Buckwell, L. Montesi, M.S. Munde, D. Gao, S. Hudziak, R.J. Chater, S. Fearn, D. McPhail, M. Bosman, A.L. Shluger, A.J. Kenyon, Nanoscale transformations in metastable, Amorph. Silicon-Rich Silica Adv. Mater. 28 (34) (2016) 7486-7493.

[9] B. Zhang, P. Kutalek, P. Knotek, L. Hromadko, J.M. Macak, T. Wagner, Investigation of the resistive switching in $\mathrm{Ag}_{\mathrm{x}} \mathrm{AsS}_{2}$ layer by conductive AFM, Appl. Surf. Sci. 382 (2016) 336-340.

[10] Y. Heo, D. Kan, Y. Shimakawa, J. Seidel, Resistive switching properties of epitaxial $\mathrm{BaTiO}_{3-\delta}$ thin films tuned by after-growth oxygen cooling pressure, PCCP 18 (1) (2016) 197-204.

[11] P. Bousoulas, J. Giannopoulos, K. Giannakopoulos, P. Dimitrakis, D. Tsoukalas, Memory programming of $\mathrm{TiO}_{2-\mathrm{x}}$ films by conductive atomic force microscopy evidencing filamentary resistive switching, Appl. Surf. Sci. 332 (2015) 55-61.

[12] Y. Xia, C. Musumeci, J. Bergqvist, W. Ma, F. Gao, Z. Tang, S. Bai, Y. Jin, C. Zhu, R. Kroon, C. Wang, M.R. Andersson, L. Hou, O. Inganäs, E. Wang, Inverted allpolymer solar cells based on a quinoxaline-thiophene/naphthalene-diimide polymer blend improved by annealing, J. Mater. Chem. A 4 (10) (2016) 3835-3843.

[13] S.K. Swami, N. Chaturvedi, A. Kumar, R. Kapoor, V. Dutta, J. Frey, T. Moehl, M. Grätzel, S. Mathew, M.K. Nazeeruddin, Investigation of electrodeposited cobalt sulphide counter electrodes and their application in next-generation dye sensitized solar cells featuring organic dyes and cobalt-based redox electrolytes, J. Power Sources 275 (2015) 80-89.

[14] S. Müller, R.-P. Baumann, T. Geßner, R.T. Weitz, Identification of grain boundaries as degradation site in n-channel organic field-effect transistors determined via conductive atomic force microscopy, Phys. Status Solidi RRL 10 (4) (2016) 339-345.

[15] C. Villeneuve-Faure, D. Le Borgne, E. Bedel-Pereira, K.I. Moineau Chane-Ching, D. Hernandez-Maldonado, I. Séguy, Cross Kelvin force microscopy and conductive atomic force microscopy studies of organic bulk heterojunction blends for local morphology and electrical behavior analysis, J. Appl. Phys. 117 (5) (2015) 055501.

[16] A. Fejfar, et al., Correlative microscopy of radial junction nanowire solar cells using nanoindent position markers, Sol. Energy Mater. Sol. Cells 135 (2015) 106-112.

[17] M. Pea, L. Maiolo, E. Giovine, A. Rinaldi, R. Araneo, A. Notargiacomo, Electrical characterization of FIB processed metal layers for reliable conductive-AFM on ZnO microstructures, Appl. Surf. Sci. 371 (2016) 83-90.

[18] Y. Zhang, Study of Schottky contact between Au and NiO nanowire by conductive atomic force microscopy (C-AFM): the case of surface states, Phys. E 69 (2015) 109-114.

[19] O. Pluchery, Y. Zhang, R. Benbalagh, L. Caillard, J.J. Gallet, F. Bournel, A.F. Lamic-Humblot, M. Salmeron, Y.J. Chabal, F. Rochet, Static and dynamic electronic characterization of organic monolayers grafted on a silicon surface, Phys. Chem. Chem. Phys. 18 (5) (2016) 3675-3684.

[20] S. Bakhti, N. Destouches, C. Hubert, S. Reynaud, F. Vocanson, T. Ondarçuhu, T. Epiciere, Growth of single gold nanofilaments at the apex of conductive atomic force microscope tips, Nanoscale 8 (14) (2016) 7496-7500.

[21] C. Ríos, R.A. Taylor, H. Bhaskaran, Color depth modulation and resolution in phase-change material nanodisplays, Adv. Mater. 28 (23) (2016) 4720-4726.

[22] G. Cantele, E. Degoli, E. Luppi, R. Magri, D. Ninno, G. Iadonisi, S. Ossicini, Firstprinciples study of n-and p-doped silicon nanoclusters, Phys. Rev. B 72 (11) (2005) 113303. 
[23] L.E. Ramos, E. Degoli, G. Cantele, S. Ossicini, D. Ninno, J. Furthmüller, F. Bechstedt, Structural features and electronic properties of group-III-, groupIV-, and group-V-doped Si nanocrystallites, J. Phys. Condens. Matter 19 (46) (2007) 466211.

[24] M. Fujii, Y. Yamaguchi, Y. Takase, K. Ninomiya, S. Hayashi, Control of photoluminescence properties of Si nanocrystals by simultaneously doping n-and p-type impurities, Appl. Phys. Lett. 85 (7) (2004) 1158-1160.

[25] D. Cavalcoli, F. Detto, M. Rossi, A. Tomasi, A. Cavallini, The electrical conductivity of hydrogenated nanocrystalline silicon investigated at the nanoscale, Nanotechnology 21 (2010) 045702.

[26] N. Brinkmann, D. Sommer, G. Micard, G. Hahn, B. Terheiden, Electrical, optica and structural investigation of plasma-enhanced chemical-vapor-deposited amorphous silicon oxynitride films for solar cell applications, Sol. Energy Mater. Sol. Cells 108 (2013) 180-188.

[27] T. Mates, P.C. Bronsveld, A. Fejfar, B. Rezek, J. Kočka, J.K. Rath, R.E.I. Schropp Detailed structural study of low temperature mixed-phase Si films by X-TEM and ambient conductive AFM, J. Non-Cryst. Solids 352 (9) (2006) 1011-1015.

[28] I. Tanaka, I. Kamiya, H. Sakaki, N. Qureshi Jr., S.J. Allen, P.M. Petroff, Imaging and probing electronic properties of self-assembled InAs quantum dots by atomic force microscopy with conductive tip, Appl. Phys. Lett. 74 (6) (1999) 844-846.

[29] N. Brinkmann, Analyse von elektrischen, optischen und strukturellen Eigenschaften von Emitter und TCO Schichten für kristalline Silizium-Heterosolarzellen, PhD thesis, University of Konstanz, 2013.

[30] R.A. Street, Hydrogenated Amorphous Silicon, Cambridge Solid State Science
Series, New York, 1991

[31] R. Rizzoli, C. Summonte, J. Plá, E. Centurioni, G. Ruani, A. Desalvo, F. Zignani, Ultrathin $\mu \mathrm{c}-$ Si films deposited by PECVD, Thin Solid Films 383 (1) (2001) 7-10.

[32] D. Cavalcoli, M. Rossi, A. Tomasi, A. Cavallini, Degeneracy and instability of nanocontacts between conductive tips and hydrogenated nanocrystalline $\mathrm{Si}$ surfaces in conductive atomic force microscopy, Nanotechnology 20 (4) (2008) 045702.

[33] B. Rezek, J. Stuchlík, J. Kocka, Microcrystalline silicon thin films studied by atomic force microscopy with electrical current detection, J. Appl. Phys. 92 (1) (2002) 587-593.

[34] A. Minj, D. Cavalcoli, A. Cavallini, Thermionic emission from the 2DEG assisted by image-charge-induced barrier lowering in AlInN/AlN/GaN heterostructures, Nanotechnology 23 (11) (2012) 115701.

[35] E.H. Rhoderick, R.H. Williams, Metal-semiconductor Contacts, second ed. Oxford Science Publications, New York, 1988.

[36] M. Ahmetoglu, S.K. Akay, Determination of the parameters for the back-toback switched Schottky barrier structures, Curr. Appl. Phys. 10 (2) (2010) 652-654.

[37] http://www.cleanroom.byu.edu/ohmic-schottky.phtml.

[38] I.F. Crowe, N. Papachristodoulou, M.P. Halsall, N.P. Hylton, O. Hulko, A.P. Knights, P. Yang, R.M. Gwilliam, M. Shah, A. Kenyon, Donor ionization in size controlled silicon nanocrystals: the transition from defect passivation to free electron generation, J. Appl. Phys. 113 (2) (2013) 024304. 